\title{
Symptom Severity Impacts Sympathetic Dysregulation and Inflammation in Post-Traumatic Stress Disorder (PTSD)
}

\author{
Ida T. Fonkoue ${ }^{1,2}$, Paul J. Marvar ${ }^{3}$, Seth Norrholm ${ }^{2,4}$, Yunxiao Li $^{5}$, Melanie L. Kankam ${ }^{1,2}$, \\ Toure N. Jones ${ }^{1,2}$, Monica Vemulapalli ${ }^{1,2}$, Barbara Rothbaum ${ }^{4}$, J. Douglas Bremner ${ }^{2,4,6}$, \\ Ngoc-Anh Le ${ }^{7}$, Jeanie Park ${ }^{1,2}$ \\ ${ }^{1}$ Renal Division, Department of Medicine, Emory University School of Medicine, Atlanta, GA \\ ${ }^{2}$ Research Service Line, Atlanta Veterans Affairs Health Care System (VAHCS), Decatur, GA \\ ${ }^{3}$ Department of Pharmacology and Physiology, Institute for Neuroscience, George Washington \\ University, Washington, DC \\ ${ }^{4}$ Department of Psychiatry and Behavioral Sciences, Emory University School of Medicine, \\ Atlanta, GA, USA \\ ${ }^{5}$ Department of Biostatistics and Bioinformatics, Rollins School of Public Health, Emory \\ University, Atlanta, GA \\ ${ }^{6}$ Department of Radiology, Emory University School of Medicine, Atlanta, GA \\ ${ }^{7}$ Biomarker Core Laboratory, Atlanta VAHCS, Decatur, GA, USA
}

\begin{abstract}
Post-traumatic stress disorder (PTSD) is associated with a greater risk of incident hypertension and cardiovascular disease. Inflammation, impaired baroreflex sensitivity (BRS) decreased parasympathetic nervous system (PNS) and overactive sympathetic nervous system (SNS) activity are suggested as contributing mechanisms. Increasing severity of PTSD symptoms has been linked to greater cardiovascular risk; however, the impact of PTSD symptom severity on inflammation and autonomic control of blood pressure has not yet been explored. We hypothesized that increasing PTSD symptom severity is linked to higher inflammation, greater SNS activity, lower PNS reactivity and impaired BRS. Seventy Veterans participated in this study: 28 with severe PTSD ((Clinical Administered PTSD Scale (CAPS)>60; S-PTSD), 16 with moderate PTSD (CAPS $\geq 45$ 560; M-PTSD) and 26 Controls (CAPS $<45$; NO-PTSD). We recorded continuous blood pressure (BP), heart rate (HR) via EKG, heart rate variability (HRV) markers reflecting PNS and muscle sympathetic nerve activity (MSNA) at rest, during arterial baroreflex sensitivity (BRS) testing via the modified Oxford technique, and during 3 min of mental stress via mental arithmetic. Blood samples were analyzed for 12 biomarkers of systemic and vascular inflammation. While BP was comparable between severity groups, HR tended to be higher ( $\mathrm{p}=0.055)$ in S-PTSD $(76 \pm 2$ beats $/ \mathrm{min})$ than in Controls $(67 \pm 2$ beats $/ \mathrm{min})$ but comparable to MPTSD (70 \pm 3 beats/min). There were no differences in resting HRV and MSNA between groups;
\end{abstract}

Address for Correspondence: Jeanie Park, M.D., Associate Professor, Division of Renal Medicine, Department of Medicine, Emory University School of Medicine, 1639 Pierce Drive, WMB 3300, Atlanta, GA 30322, Phone: (404) 727-1386, jeanie.park@emory.edu. 
however, cardiovagal BRS was blunted $(\mathrm{p}=0.021)$ in S-PTSD $(10 \pm 1 \mathrm{~ms} / \mathrm{mmHg})$ compared to controls $(16 \pm 3 \mathrm{~ms} / \mathrm{mmHg})$ but comparable to M-PTSD $(12 \pm 2 \mathrm{~ms} / \mathrm{mmHg})$. Veterans in the S-PTSD group had a higher $(\mathrm{p}<0.001)$ combined inflammatory score compared to both M-PTSD and NOPTSD. Likewise, while mental stress induced similar SNS and cardiovascular responses between the groups, there was a greater reduction in HRV in S-PTSD compared to both M-PTSD and NOPTSD. In summary, individuals with severe PTSD symptoms have higher inflammation, greater impairment of BRS, a trend towards higher resting HR and exaggerated PNS withdrawal at the onset of mental stress that may contribute to cardiovascular risk in severe PTSD.

\section{Keywords}

PTSD severity; autonomic activity; baroreflex sensitivity; inflammation; blood pressure

\section{INTRODUCTION}

PTSD is associated with an increased risk for developing hypertension and cardiovascular disease and is a growing public health concern (Edmondson \& von Känel, 2017). PTSD affects up to $20 \%$ of military service members, and is also high in the general population, affecting about $7 \%$ of adult Americans (Kessler et al., 2005). In addition to debilitating psychological symptoms and adverse effects on quality of life, multiple large epidemiologic studies have demonstrated that PTSD is independently associated with an increased risk of hypertension and cardiovascular disease (Bedi \& Arora, 2007; Edmondson \& Cohen, 2013; Vaccarino et al., 2013). In addition, studies have shown that the severity of PTSD symptoms impacts risk of cardiovascular disease, such that patients have a step-wise increase in cardiovascular disease risk with increasing PTSD symptom severity (Howard et al., 2018).

The mechanisms underlying increased hypertension and cardiovascular risk in PTSD remain unclear, but prior studies including from our laboratory and others have reported alterations in autonomic function, including decreased resting parasympathetic nervous system (PNS) activity and heightened reactivity of the sympathetic nervous system (SNS) during mental stress in PTSD (Buckley \& Kaloupek, 2001; Pole, 2007; Park et al., 2017). One potential mechanism underlying abnormalities in autonomic reactivity is impaired arterial baroreflex sensitivity (BRS) which has been shown to be impaired in military Veterans with PTSD (Park et al., 2017). Importantly, both exaggerated neurocirculatory reactivity (Matsukawa et al., 1991b) and blunted BRS (Matsukawa et al., 1991a) are independently associated with hypertension and cardiovascular disease. However, the potential impact of PTSD symptom severity on neural cardiovascular function and regulation remains unknown. Since cardiovascular risk increases with increasing PTSD symptomatology, it is plausible that PTSD patients have greater derangements in SNS and PNS function and regulation with higher PTSD symptom burden. Furthermore, PTSD is also characterized by increased inflammation (Gill et al., 2009; Pace \& Heim, 2011; Baker et al., 2012) that could contribute mechanistically to impaired arterial BRS at the level of vascular nerve endings or both afferent and efferent pathways involved in baroreflex control (Bristow et al., 1969; Takagishi et al., 2010; Marvar et al., 2016), as well as increased central SNS activation directly. Therefore, we hypothesized that military Veterans with PTSD have higher SNS activity, 
greater inflammation and greater impairment of arterial BRS with worsening PTSD symptom severity. We further hypothesized that increasing PTSD symptom severity is linked to BP reactivity, SNS activation and PNS withdrawal during acute mental stress in Veterans with PTSD.

\section{METHODS}

\subsection{Ethical Approval}

This study conformed to the standards set by the Declaration of Helsinki and was approved by the Emory University Institutional Review Board and the Atlanta Veterans Affairs Health Care System (VAHCS) Research and Development Committee. All participants provided written informed consent for study participation via forms approved by the regulatory committees mentioned above.

\subsection{Study Population}

The study population consisted of 70 military Veterans: 28 patients with severe PTSD (SPTSD), 16 patients with moderate PTSD (M-PTSD) and 26 age-matched controls without PTSD (NO-PTSD). All study participants (both PTSD and Controls) were physically healthy post-9/11 Veterans, without hypertension or other medical comorbidities. Participants were recruited from mental health clinics serving post-9/11 Veterans at the Atlanta Veterans Affairs (VA) Health Care Systems hospital and surrounding clinics. Exclusion criteria for all participants included hypertension, diabetes, heart or vascular disease, illicit drug use, excessive alcohol use ( $>2$ drinks per day), hyperlipidemia, autonomic dysfunction, medications known to affect the SNS (clonidine, $\beta$-blockers, angiotensin-converting enzyme inhibitors), treatment with monoamine oxidase inhibitors and any serious systemic disease. Participants with a prior documented diagnosis of PTSD from medical records were recruited to the PTSD groups and those without a prior diagnosis were recruited to the Control (NO-PTSD) group.

\subsection{Measurements and Procedures}

2.3.1. CAPS and PCL-M.-The diagnosis and severity of PTSD was confirmed in PTSD patients and excluded in Controls using the Clinician Administered PTSD Scale for Diagnostic Statistical Manual for Mental disorders, fourth edition (DSM-IV) (CAPS)-IV (Blake et al., 1995) and/or the PTSD Checklist Military version (PCL-M) (Blanchard et al., 1996). The CAPS is a validated and reliable measure of PTSD which can be used for diagnosis as well as quantification of symptom severity within the intrusion, avoidance, and hyperarousal domains (Blake et al., 2000). The PCL is a validated and reliable self-report measure of PTSD symptoms which provides a continuous measure of symptom severity (Bovin et al., 2016). Both the CAPS-IV and PCL-M have excellent psychometric properties with high inter-rater reliability, test-retest reliability, and internal consistency (Blake et al., 1995; Blanchard et al., 1996). The PCL and the CAPS scores have been shown to be highly correlated ( $\mathrm{r}=0.929)$ (Blanchard et al., 1996). CAPS-IV was administered by a single, trained investigator specifically for the current study. Patients required a CAPS-IV and/or PCL-M severity score of $\geq 45$ to confirm the presence of PTSD (Blanchard et al., 1996; Weathers et al., 2001). Those with a CAPS-IV or PCL-M $>60$ were classified as having severe PTSD (S- 
PTSD) while a CAPS-IV or PCL-M $\geq 45 \square 00$ was classified as moderate PTSD (M-PTSD). The absence of PTSD in the NO-PTSD group was confirmed with a CAPS-IV score of $<45$. The use of the two different scales (PCL-M and CAPS) was evenly balanced across the three groups.

\subsubsection{Blood pressure (BP), heart rate (HR) and respiratory rate (RR).-Three} seated BP measurements separated by 5 min were taken during at least 2-3 separate screening visits in all 70 participants. A single study coordinator took all BP measurements using the standard American College of Cardiology (ACC)/American Heart Association (AHA) guideline technique (Whelton et al., 2018) with an appropriately sized cuff placed on the upper arm with the arm resting at heart level after at least 5 min of quiet rest using an automated digital BP device (Omron, HEM-907XL, Omron Healthcare, Kyoto, Japan). During the experimental protocol, beat-to-beat arterial BP was measured continuously and noninvasively using digital pulse photoplethysmography (CNAP Monitor 500, CNSystems, Graz, Austria) as previously described (Fonkoue et al., 2018a). Absolute values of BP were calibrated with upper arm BP readings using an internal calibration system at the start and every 15 min throughout the study. This device has been validated to reflect accurate absolute and beat-to-beat fluctuations in BP when compared with invasive intra-arterial catheter readings (Ilies et al., 2012). HR was measured using continuous electrocardiography with a Bio Amp (model ML 132, ADInstruments, Colorado Springs, CO). Respiratory rate (RR) was continuously monitored via a respiratory belt pressure transducer placed around the upper abdomen (Pneumotrace II, ADInstruments).

2.3.3. Muscle sympathetic nerve activity (MSNA).-Multiunit postganglionic sympathetic nerve activity directed to muscle (MSNA) was recorded using microneurography, as described previously (Wallin \& Fagius, 1988). A tungsten microelectrode (tip diameter 5-15 $\mu \mathrm{m}$; Bioengineering, University of Iowa, Iowa City, IA) was inserted into the peroneal nerve with a reference microelectrode inserted in close proximity. The efferent nerve signals were amplified (total gain 50,000-100,000), filtered (700-2,000 Hz), rectified, and integrated (time constant $0.1 \mathrm{~s}$ ) to obtain a mean voltage display (Nerve Traffic Analyzer, model 662C-4; Bioengineering, University of Iowa) of MSNA that was recorded using LabChart 7 (PowerLab 16sp, ADInstruments, Sydney, Australia) along with continuous ECG, BP, and RR. All MSNA recordings met previously established quality standards (Mano et al., 2006). MSNA was ascertained by verifying entrainment to the HR with bursts falling between R-R intervals with a 3:1 burst-to-baseline ratio and activity increasing with apnea and Valsalva. Skin sympathetic nerve activity was also ruled out by verifying lack of reactivity to acoustic startle. All MSNA data were analyzed by a single investigator blinded to the participant's group status.

\subsubsection{Arterial baroreflex sensitivity (BRS) using the Modified Oxford} technique.-The gold-standard method for evaluation of arterial BRS was performed by measuring changes in MSNA and R-R interval during arterial BP changes induced by sodium nitroprusside (NTP) and phenylephrine (PE) (Rudas et al., 1999). NTP $100 \mu \mathrm{g}$ in 10 $\mathrm{ml}$ of normal saline (NS) was bolused through an antecubital intravenous (IV) catheter, followed $60 \mathrm{~s}$ later by an IV bolus of PE (150 $\mu \mathrm{g}$ in $10 \mathrm{ml}$ of NS) during continuous MSNA, 
ECG, and hemodynamic monitoring. Medications were room temperature at the time of administration. These medications induce a decrease of $\sim 15 \mathrm{mmHg}$, followed by an increase above baseline of $\sim 15 \mathrm{mmHg}$ in arterial BP (Bonyhay \& Freeman, 2004).

2.3.5. Inflammatory biomarkers. - Venous blood samples were collected in all participants on the day of the experiment prior to any instrumentation and tested for the following biomarkers: a) highly sensitive C-reactive protein (hsCRP) as a general marker of systemic inflammation; b) pro-inflammatory cytokines and chemokines including interferon (IFN), tumor necrosis factor a (TNFa), interleukin-1 $\beta$ (IL-1 $\beta$ ), interleukin-2 (IL-2), interleukin 6 (IL-6), and monocyte chemoattractant protein-1 (MCP-1); interleukin 1 receptor antagonist (IL-1RA), tumor necrosis factor receptor II (TNF-RII); c) vascular inflammatory biomarkers including lipoprotein-associated phospholipase A2 (Lp-PLA2), Eselectin and intercellular adhesion molecule-1 (ICAM-1). Blood was collected in EDTAtreated whole blood tubes and were centrifuged for 15 minutes at 2200-2500 RPM. The collected samples were stored at $-80^{\circ} \mathrm{C}$ for subsequent immunohistochemical analyses. HsCRP and Lp-PLA2 were tested for all participants. However, the rest of the inflammatory biomarkers were only tested for a subset of 50 participants (14 S-PTSD, 12 M-PTSD and 24 NO-PTSD). HsCRP was determined by immunoturbidometric method on the Beckman AU460 (Beckman Diagnostics, LaBrea, CA, USA) using reagent kits from Sekisui Diagnostics (Lexington, MA, USA). Pro-inflammatory cytokines (INF, TNFa, IL-1 $\beta$, IL-2, IL-6), chemokine (MCP-1), anti-inflammatory cytokines (IL-6R, IL-1RA, TNF-RII), adhesion molecules ICAM-1 (intercellular adhesion molecule-1), and E-selectin (CD62E; ESEL) were measured in duplicate in the biomarker core laboratory at Emory University, using the Meso Scale Discovery (MSD) human multiplex ELISA. This electrochemiluminescence system has been validated by comparisons with traditional ELISA and produces measurements that have high content validity (Fichorova et al., 2008; Leviton et al., 2011). Human E-selectin and ICAM-1 in plasma were measured using the human multiple V-PLEX kit (Meso-Scale Discovery, Rockville, MD) according to the manufacturer's protocol. The signals were read on the MSD QuickPlex instrument and the concentration was evaluated on the MSD software platform. The activity of lipoproteinassociated phospholipase-A2 (Lp-PLA2) was measured at the Biomarker Core laboratory of the Atlanta VA, using a PAF-AH activity assay kit, which produces results based on a colorimetric shift (Biovision, Milpitas, CA), according to the manufacturer's instructions. Performance characteristics for the Lp-PLA2 test were established using the enzymatic method Beckman Coulter AU400, a dual monoclonal antibody immunoassay standardized to recombinant Lp-PLA2 (PLAC test, diaDexus, Inc) (Dada et al., 2002). To assess intra-assay precision and total variability for Lp-PLA2 measurement, five human serum samples and two buffer controls with Lp-PLA2 activity distributed throughout the calibration range of the assay were measured in 40 separate assays to determine the intra-assay coefficient of variation (Le et al., 2015).

2.3.6. Heart rate variability (HRV).- - HRV was derived from the continuous EKG recordings and quantified in the time domain as standard deviation of R-R intervals (SDNN) and root mean square of differences in successive R-R intervals (RMSSD). HRV was quantified in the frequency domain using a fast-Fourier transformation over the measured 
time period as HF power $(0.15-0.40 \mathrm{~Hz})$. These HRV measures have been validated as reflecting cardiac PNS activity (Malik et al., 1996)

2.3.7. Mental stress via mental arithmetic.-As previously described (Fonkoue et al., 2018b) participants were asked to serially subtract a one- or two-digit number from a three- or four-digit number and were urged to do so as quickly and accurately as possible, for a duration of $3 \mathrm{~min}$. An investigator used flash cards with a three- or four-digit number and were urged by two additional study team members in white coats to answer 'faster' and 'get it right'.

\subsection{Experimental Protocol}

2.4.1. Screening visits.-All participants presented for two or three screening visits prior to experimental procedures. During the screening visits, BP was taken a total of three times (separated by $5 \mathrm{~min}$ ) and averaged to ensure the absence of hypertension and obtain baseline hemodynamic values. Hypertension was defined as 1) a prior diagnosis of hypertension and/or treatment with antihypertensive medications; and/or 2) a resting blood pressure $>140 / 90 \mathrm{~mm} \mathrm{Hg}$ (James et al., 2014) during the screening visits in patients without a prior diagnosis of hypertension. CAPS-IV and/or the PCL-M was administered by a single investigator during the screening visits to confirm the diagnosis and severity of PTSD in patients and to exclude the diagnosis of PTSD in Controls.

2.4.2. Experimental study visit.-All participants were studied in the morning, after abstaining from food, caffeine and alcohol for at least $12 \mathrm{~h}$, as well as smoking and exercise for at least $24 \mathrm{~h}$. The study room was quiet, semi-dark and temperate $\left(\sim 21^{\circ} \mathrm{C}\right)$. Participants were placed in a supine position on a comfortable stretcher. A 20-gauge IV catheter was placed into the antecubital vein of the arm and blood was obtained for inflammatory biomarkers. Finger cuffs were fitted and placed on the fingers of the dominant arm for continuous beat-to-beat arterial BP measurements, and an upper arm cuff was placed for intermittent automatic calibrations with the finger cuffs. ECG patch electrodes were placed for continuous ECG recordings and a belt-type sensor was placed for monitoring continuous respiratory rates. The leg was positioned for microneurography, and the tungsten microelectrode was inserted and manipulated to obtain a satisfactory nerve recording. After $10 \mathrm{~min}$ of rest, baseline BP, HR and MSNA were recorded continuously for $15 \mathrm{~min}$. After baseline measurements, BRS testing was performed by infusing IV boluses of $100 \mu \mathrm{g}$ of nitroprusside, followed $60 \mathrm{~s}$ later by $150 \mu \mathrm{g}$ of phenylephrine, as described above. After 15 minutes of rest to ensure return to baseline conditions, participants underwent 3 minutes of mental stress via mental arithmetic as described above. After 5 minutes of recovery data were obtained, participants were observed for an additional 15 minutes and then discharged.

\subsection{Data Analysis}

\subsubsection{Hemodynamics, Muscle sympathetic nerve activity and BRS}

assessment.-For all baseline analyses, we used the last $10 \mathrm{~min}$ of the 15 -min baseline recording to ensure true resting state. MSNA, BP, and ECG data were exported from Labchart to WinCPRS (Absolute Aliens, Turku, Finland) for analysis as previously described (Park et al., 2017). The continuous arterial BP waveforms were analyzed for beat- 
to-beat changes in systolic BP (SAP), diastolic BP (DAP), and mean arterial pressure (MAP). R-waves were detected and marked from the continuous ECG recording. MSNA bursts were automatically detected by the program using the following criteria: burst-tonoise ratio of 3:1 within a 0.5 -s search window with an average latency of 1.2-1.3 s in burst occurrence from the previous R-wave. After automatic detection, the ECG and MSNA neurograms were visually inspected for accuracy of detection by a single investigator without knowledge of the PTSD or the severity status. MSNA was expressed as burst frequency (bursts per minute) and burst incidence (bursts per 100 heartbeats). Sympathetic BRS was quantified as the slope of the linear relationship between MSNA burst incidence and DAP during pharmacological manipulation of BP. Cardiovagal BRS was quantified as the slope of the linear relationship between R-R interval and SAP. Only slope values with a correlation value $>0.5$ were included. At least 2 min of data (Park et al., 2017), including both the decreases and increases in BP induced pharmacologically were analyzed for each overall BRS assessment.

2.5.2. Statistical Analysis.-Data were analyzed statistically using commercial software (SPSS 25.0; IBM SPSS, Armonk, NY) and the R Language and Environment for Statistical Computing (R Foundation for Statistical Computing, Vienna, Austria). All data were tested for normal distribution. Multivariate analysis of variance (ANOVAs) were used to compare variables (BP, MSNA, BRS and biomarkers) between the three groups. A principal component (PC) analysis (Jolliffe \& Cadima, 2016) was used to create a combined inflammatory score that aggregates all inflammatory markers tested in the subset of 50 participants. PC analysis is a well-known dimension-reduction tool for multivariate data, reorganizing raw data to summary statistics in a much lower dimension. Joint associations between PTSD and inflammatory markers were examined through principal component (PC) analysis and ANOVAs. Estimation and inference of linear mixed models (LMM) was performed using the R environment as previously described (Fonkoue et al., 2018a). LMM was used to compare differences in "slopes" of mental stress responses between the groups, which indicate rates of change during the intervention. A $\chi$ 2-squared test for independence was used to compare all categorical variables. An independent t-test was performed as post hoc analysis to compare the continuous variables, including resting hemodynamics, MSNA, BRS and individual inflammatory biomarkers between S-PTSD, M-PTSD and NO-PTSD groups. Pearson's correlation coefficients were calculated to examine the relationships between variables. Significance level was set at $a<0.05$.

\section{RESULTS}

\subsection{Demographics, Resting BP and HR}

A total of seventy Veterans (S-PTSD, N=28; M-PTSD, N=16; and NO-PTSD, N=26) were enrolled in the study. Among the 70, the diagnosis or exclusion, and symptom severity of PTSD were confirmed by both CAPS-IV and PCL-M in N=23, CAPS-IV only in N=11 and PCL-M only in N=36 participants (Table 1). CAPS-IV and PCL-M scores in the subset of 23 were highly correlated $(\mathrm{r}=0.806,<0.001)$. 
As shown in Table 1, groups were well-matched for age, body mass index (BMI), race and sex. The majority of participants in each group were African-American and male. As expected, the CAPS-IV and PCL-M scores were higher in S-PTSD versus M-PTSD versus NO-PTSD. There were no differences in proportion of smokers or major depressive disorders (MDD) between groups, and there was a trend towards a greater proportion of participants on selective serotonin receptor inhibitors (SSRI) in both PTSD subgroups compared to the NO-PTSD group ( $\mathrm{p}=0.061$ ). There was a greater use of prazosin, an alpha-1 adrenergic receptor blocker, at night for nightmares in S-PTSD and M-PTSD compared to NO-PTSD ( $\mathrm{p}=0.007)$. Resting BP was similar between the groups. SAP ranged from 100 to $139 \mathrm{mmHg}$ for the S-PTSD group, 101 to $144 \mathrm{mmHg}$ for the M-PTSD and 99 to $143 \mathrm{mmHg}$ for the NO-PTSD; DAP ranged from 63 to $90 \mathrm{mmHg}$ for the S-PTSD group, 57 to $97 \mathrm{mmHg}$ for the M-PTSD and 62 to $97 \mathrm{mmHg}$ for the NO-PTSD. While baseline BP was comparable between the groups, HR ( $\mathrm{p}=0.055)$, however, tended to be higher in S-PTSD compared to M-PTSD and NO-PTSD.

\subsection{Baseline Autonomic Function}

Baseline MSNA burst frequency ( $\mathrm{p}=0.443$ ) and burst incidence $(\mathrm{p}=0.477)$, reflecting resting SNS activity, were not different between S-PTSD, M-PTSD, and NO-PTSD groups (Table 1). Suitable MSNA recordings were not obtained in 9 participants; therefore, the MSNA results are given for a subset of 61 participants (26 S-PTSD, 13 M-PTSD and 22 NOPTSD). Also shown in Table 1 are the time domain (SDNN and RMSSD) measures of HRV reflecting PNS control of the heart for all 70 participants. Resting SDNN ( $p=0.470)$ and RMSSD ( $\mathrm{p}=0.368$ ) were also not different between S-PTSD, M-PTSD and NO-PTSD groups.

\subsection{Arterial BRS}

Figure 1 shows the results for cardiovagal BRS (panel $A$ ) and sympathetic BRS (panel $B$ ), quantified during pharmacological manipulation of BP as described above. Cardiovagal BRS was lower $(\mathrm{p}=0.021)$ in S-PTSD compared to M-PTSD and NO-PTSD. A post hoc analysis revealed that S-PTSD was different from NO-PTSD but not from M-PTSD. Likewise, sympathetic BRS tended to be blunted $(\mathrm{P}=0.066)$ in S-PTSD when compared to M-PTSD and NO-PTSD.

\subsection{Inflammatory biomarkers}

Figure 2 depicts the results of a principal component (PC) analysis (Jolliffe \& Cadima, 2016) used to create a combined inflammatory score for each participant that aggregates the 11 inflammatory biomarkers (IFN, TNFa, IL-1 $\beta$, IL-2, IL-6, IL1-RA, IL-6R, TNF-RII, MCP-1, E-selectin and ICAM-1) tested in the subset of 50 participants. The scale used did not affect the PC analysis results. The combined inflammatory scores were correlated with CAPS scores $(r=0.456, p=0.033)$ as well as with PCL-M scores $(r=0.407, p=0.006)$. The $S$ PTSD group had a combined inflammatory score higher $(\mathrm{p}<0.001)$ than M-PTSD and NOPTSD. This difference remained even when adjusting for SSRI and smoking $(\mathrm{p}=0.006)$ and also when adjusted for MDD ( $\mathrm{p}<0.001)$. The aggregate PC-scores correlated with CAPS-IV scores $(R=0.456 ; p=0.033)$ and PCL-M scores $(R=0.407 ; p=0.006$; data not shown $)$. Individual results for inflammatory biomarkers that were different based on PTSD severity 
are shown in Figure 3. hsCRP (panel $A$ ), a general marker of systemic inflammation, was significantly higher $(\mathrm{p}=0.022)$ in S-PTSD $(2.21 \pm 0.5 \mathrm{mg} / \mathrm{L})$ compared to M-PTSD $(1.0$ $\pm 0.2 \mathrm{mg} / \mathrm{L})$ and NO-PTSD $(0.9 \pm 0.3 \mathrm{mg} / \mathrm{L})$. Pro-inflammatory cytokines and their associated signaling receptors TNFa and TNF-RII (panels $B$ and $C$, respectively), IL-1 $\beta$ and IL-1RA (panels $D$ and $E$, respectively) and IL-6 and IL-6R (panel $F$ and $G$, respectively) were higher in S-PTSD compared to NO-PTSD. hsCRP, TNFa, TNF-RII, IL-6, and ICAM-1 were also higher in S-PTSD compared to both M-PTSD and NO-PTSD, while IL-6R was higher in S-PTSD and M-PTSD compared to NO-PTSD. IFN, IL-2, and MCP-1 were comparable ( $>0.05)$ between the groups (results not shown). The vascular inflammatory biomarker ICAM-1 (panel $H$ ), was significantly higher ( $=0.012)$ in S-PTSD $(619 \pm 49 \mathrm{ng} / \mathrm{mL})$ compared to M-PTSD $(440 \pm 25 \mathrm{ng} / \mathrm{mL})$ and NO-PTSD (508 $\pm 24 \mathrm{ng} /$ $\mathrm{mL}$ ). However, vascular biomarkers Lp-PLA2 and E-selectin were comparable ( $p>0.05)$ between the groups (data not shown). When analyses for individual inflammatory biomarkers were further adjusted for MDD, results remained largely the same. TNFa $(\mathrm{p}<0.001$ and 0.002$)$ and TNF-RII $(\mathrm{p}=0.015$ and 0.045$)$ remained elevated in S-PTSD compared to M-PTSD and NO-PTSD, respectively. IL-6 $(\mathrm{p}=0.035)$ and ICAM-1 $(\mathrm{p}=0.009)$ remained higher in S-PTSD compared to M-PTSD; IL-1 $\beta$ ( $\mathrm{p}=0.029)$ and IL-6R $(\mathrm{p}=0.030)$ remained higher in S-PTSD compared to NO-PTSD. However, IL-1RA ( $\mathrm{p}=0.05)$ tended to be higher in S-PTSD than in M-PTSD, and there was no difference in hsCRP levels between groups ( $p>0.05$ ) after adjustment for MDD.

\subsection{Mental stress}

During 3 min of MA, there was no significant difference in SAP (Figure 4A; time*PTSD, $\mathrm{p}=0.133$ ), DAP (Figure 4B; time*PTSD, $\mathrm{p}=0.507$ ) or HR (Figure 4C; time*PTSD, $\mathrm{p}=0.522$ ) responses amongst S-PTSD, M-PTSD and NO-PTSD groups. There was also no difference in MSNA reactivity (Figure 4D; time*PTSD, $\mathrm{p}=0.497$ ) during MA between the three groups. However, there was a significantly greater decrease in SDNN during MA in S-PTSD compared to M-PTSD and NO-PTSD (Figure 4E; time*PTSD, p=0.038), while RMSSD (Figure 4F; time*PTSD, $\mathrm{p}=0.101$ ) reactivity was comparable between the groups.

\section{DISCUSSION}

In the current study, we examined the effects of PTSD symptom severity on the cardiovascular, sympathetic and inflammatory state of post-9/11 veterans with PTSD. We report for the first time that increasing PTSD symptom severity is linked to increasing resting HR, greater impairment of arterial BRS, higher levels of inflammation and exaggerated reductions in parasympathetic activity during mental stress. Specifically, we report that: 1) resting sympathetic activity was similar between the groups; 2) HR tended to be elevated in S-PTSD compared to NO-PTSD; 3) cardiovagal BRS was reduced and sympathetic BRS tended to be reduced in S-PTSD compared to NO-PTSD; 4) systemic and vascular markers of inflammation were increased with increasing PTSD symptom severity; and 5) PNS withdrawal during mental stress was exaggerated in S-PTSD compared to MPTSD and NO-PTSD. These results suggest that increasing severity of PTSD symptoms is linked to greater autonomic dysfunction and inflammation. Therefore, the blunted BRS and inflammation previously described in PTSD patients (Edmondson \& von Känel, 2017; Park 
et al., 2017), as a potential mechanism for increased cardiovascular risk, may be largely driven by those with the most severe PTSD symptoms. Taken together, our current findings shed light on the link between the severity of psychological symptoms of PTSD and the risk of hypertension and cardiovascular disease.

PTSD is a psychiatric disorder affecting as many as $20 \%$ of Veterans (Seal et al., 2009) with symptoms including avoidance, hyperarousal, reexperiencing of trauma and negative feelings. In a recent representative sample of almost 200,000 veterans of the wars in Iraq and Afghanistan, Burg et al observed a $24 \%-46 \%$ greater risk for incident hypertension associated with untreated PTSD (Burg et al., 2017). Prior studies have reported increased resting blood pressure and HR in PTSD compared to controls (Shalev et al., 1998; Buckley $\&$ Kaloupek, 2001; Bedi \& Arora, 2007). In contrast, we previously showed that in a cohort of combat veterans, resting BP and HR were not different between PTSD and controls (Park et al., 2017). In the present study, resting HR tended to be higher in severe PTSD compared to controls, but not different from moderate PTSD. It is possible that this difference in resting HR was not detected previously (Park et al., 2017) because the severity of PTSD was not considered in the previous analysis. Higher resting HR has previously been shown to be a marker of future cardiovascular risk (Hansen et al., 2008; Woodward et al., 2014; Zhang et al., 2016). In addition, increased resting heart rate after trauma (Shalev et al., 1998) and lower HRV (Minassian et al., 2014; Minassian et al., 2015) are predictors of the subsequent development of chronic PTSD. Although the SNS is responsible for $20 \%$ of HR control under normal conditions (White \& Raven, 2014), its influence may be significantly higher under pathologic conditions such as PTSD (Tadic et al., 2018). It is also important to note that $32 \%$ of participants with severe PTSD and $19 \%$ of participants with moderate PTSD were on the alpha- 1 adrenergic receptor blocker Prazosin. While Prazosin causes relatively less reflex tachycardia compared to other alpha blockers (Reid \& Vincent, 1986), the use of prazosin may have contributed to higher resting heart rates in severe PTSD.

Currently, the pathophysiological mechanisms by which PTSD is independently related to increased hypertension and cardiovascular disease risk are still under investigation, but SNS overactivity is thought to be an underlying mechanism (Bedi \& Arora, 2007; Pole, 2007). Previous studies have described an autonomic imbalance in PTSD characterized by a decrease in the low frequency of heart rate variability (HRV) (Chang et al., 2013; Shah et al., 2013) and an increase in plasma (Bremner et al., 1996), urinary (Wingenfeld et al., 2015), and cerebrospinal fluid (Geracioti et al., 2001) catecholamines suggestive of exaggerated SNS activation. In our previous studies, where SNS activity was assessed using direct, intraneural measures of MSNA via microneurography, heightened SNS activity at rest was not apparent in PTSD, although PTSD patients had exaggerated MSNA reactivity during mental stress. The current data also show, as previously reported (Park et al., 2017), that resting MSNA is similar in PTSD and controls regardless of the severity of PTSD symptoms. It is important to note that MSNA in the general population is very variable between individuals (Carter \& Ray, 2009), remaining often comparable at rest between atrisk and not-at-risk populations (Ray \& Monahan, 2002; Fonkoue et al., 2016). Our findings suggest that this might also be the case in PTSD and that the increased HR we observed in participants with severe PTSD is possibly driven by differences in baroreceptor control. Similar to MSNA, HRV (SDNN, RMSSD) was comparable between the groups at rest 
suggesting that in this cohort of PTSD individuals, those with more severe PTSD symptoms did not have a greater impairment in HRV measures of PNS activity at baseline. We previously reported impaired cardiac PNS activity in PTSD individuals with concomitant prehypertension (Fonkoue et al., 2018b); therefore, it is possible that in the absence of elevated resting blood pressure, PTSD is not associated with significant impairment of PNS activity in the resting state. The failure of the baroreflex to elicit the appropriate changes in SNS activity and parasympathetic control of the heart could be a possible mechanism for the increased HR in severe PTSD.

Decreased arterial baroreflex sensitivity is an independent risk factor for hypertension and is associated with poorer clinical outcomes (Bristow et al., 1969; Nasr et al., 2005). We previously demonstrated that PTSD patients have blunted baseline sympathetic and cardiovagal BRS compared to controls (Park et al., 2017). Interestingly, the current report demonstrates that impairment in cardiovagal BRS is largely driven by those with severe PTSD, as cardiovagal BRS remained intact in moderate PTSD. Blunted cardiovagal BRS has been described in other patient populations characterized by increased CVD risk like hypertension (Bristow et al., 1969), atherosclerosis (Nasr et al., 2005), and chronic kidney disease (Johansson et al., 2010). These findings suggest that greater cardiovascular disease risk associated with greater PTSD symptom severity may be linked to greater impairment in regulation of the autonomic nervous system by the arterial baroreflexes.

Given recent reports linking inflammation, MSNA and BRS (Fonkoue et al., 2019), we also explored the link between PTSD symptom severity and inflammation. Chronic inflammation could contribute mechanistically to BRS dysfunction via its direct effect on the vasculature, compromising the baroreceptor nerve endings or affecting its afferent and efferent tracts in the central nervous system prior to the development of hypertension (Chapleau et al., 2001). Furthermore, chronic low-grade inflammation contributes to the pathogenesis of atherosclerosis, the precursor of coronary heart disease (Golia et al., 2014). A recent study by Vaccarino et al conducted in 562 twins (281 pairs discordant for PTSD) revealed that the incidence of coronary disease was more than double in twins with PTSD (22.6\%) than those without PTSD (8.9\%) (Vaccarino et al., 2013). Prior literature has reported a proinflammatory state in PTSD (von Kanel et al., 2007; von Kanel et al., 2010; Park et al., 2017). Some of the inflammatory markers elevated in PTSD such as C-reactive protein (Kaptoge et al., 2010), IL-1(Herder et al., 2017) and IL-6 (Sarwar et al., 2012) have been linked to the development hypertension and cardiovascular disease. In the current study, we tested multiple pro-inflammatory cytokines and chemokine vascular biomarkers, allowing us to assess a global inflammatory score, which was higher with increasing severity of PTSD, even when adjusting for MDD. These results support previous reports by Lindqvist et al. (Lindqvist et al., 2014) and demonstrate that severity of PTSD symptoms impacts the degree of inflammation in PTSD.

More specifically, we found in multivariate analyses that systemic and vascular markers of inflammation were higher in severe PTSD. Particularly, we found elevated levels of TNFa, IL-1 $\beta$ and IL-6 and their related cytokine receptors (TNFRII, IL6R, IL1RA) in in severe PTSD. TNFa and IL-1 $\beta$ have been shown to have synergistic inflammatory effects and both cytokines also induce the production of IL-6 (Neta et al., 1992). Von Känel et al. also 
reported a dose-response relationship between severity of PTSD symptoms and inflammation, including increased levels of TNF $a$ and IL1 $\beta$ (von Kanel et al., 2010). Our current results highlight that chronic inflammation in severe cases of PTSD is wide-spread, systemic and vascular and may contribute to impairments in BRS and changes in resting HR. Additionally, the vascular inflammatory marker ICAM-1 was higher in the severe PTSD group compared to the moderate PTSD and control groups in our cohort. Previous reports support a role for cell adhesion molecule (CAM)-mediated leukocyte adhesion in the development of early vascular lesions (Krieglstein and Granger 2001). CAMs are increasingly viewed as critical participants in the vascular dysfunction and tissue injury that are associated with a wide variety of inflammatory and cardiovascular diseases.

Furthermore, long term inflammation has been linked to longitudinal increases in arterial stiffness, a risk factor for hypertension (Tomiyama et al., 2017). While the majority of inflammatory biomarkers were elevated in severe PTSD, we did not find a difference in LpPLA2 and E-selectin levels between the groups in our cohort. Lp-PLA2 is an enzyme produced in cells involved in the atherosclerotic process and is mainly bound to LDL in the circulation, which may play less of a role in the pathogenesis of cardiovascular risk in PTSD. E-selectin, on the other hand, is only expressed on endothelial cells after activation by IL- $1 \beta$ or TNF $\alpha$; while these cytokines were elevated in severe PTSD, levels may not have been high enough to induce significant expression of E-Selectin. Taken together, the overall increase in inflammatory cytokines in PTSD patients with high PTSD symptom severity scores may be mechanistically linked to autonomic dysfunction and higher risk of progression to overt hypertension in this subgroup of PTSD patients (Rusch et al., 2019). Moreover, these data highlight the importance and potential utility of an inflammatory score or index in this patient population which could be used as an additional important prognostic biomarker to assess severity of cardiovascular disease risk in PTSD.

Prior work (Park et al., 2017) has shown that although resting MSNA is not different between PTSD patients and controls without PTSD, MSNA reactivity during mental stress was exaggerated in PTSD. Interestingly, the current results show that increasing PTSD severity does not augment the SNS reactivity that was previously shown in PTSD versus controls, but increasing PTSD symptom severity does result in a greater reduction in HRV during mental stress in those with severe PTSD. These findings suggest that in addition to heightened SNS reactivity characteristic of PTSD patients, increasing symptom severity is associated with greater PNS withdrawal during mental stress. Importantly, there were no differences in hemodynamic reactivity between severity groups, suggesting that PNS withdrawal did not translate to greater blood pressure or heart rate response to mental stress in severe PTSD. However, lower HRV, and abnormal neurocardiovascular reactivity independent of blood pressure have been linked to greater increases in cardiovascular disease risk (Chida \& Steptoe, 2010; Hillebrand et al., 2013) and may be one mechanism underlying progressive increases in cardiovascular disease risk with increasing PTSD symptom severity.

We recognize several limitations to our study. First, we were not able to obtain CAPS-IV scores on all participants; the use of two different scales for the assessment of PTSD severity was a limitation. The CAPS remains the gold standard for PTSD diagnosis and assessment of symptom severity. However, the PCL-M and CAPS-IV scores were highly correlated in 
the current study, as has also been previously described (Blanchard et al., 1996). Second, we were unable to run the mesoscale inflammatory biomarker analysis on all 70 participants which would have given us a larger sample for the inflammatory score. However, even with the subset of 50, we observed a difference between the participants with severe PTSD symptoms compared to those with moderate symptoms. Third, given our cutoffs scores for the three groups, the control group may have included some cases of sub-threshold PTSD which may have reduced the detection of differences in physiologic measures between the control and moderate PTSD groups. However, our analyses still suggest that increasing PTSD symptom burden is associated with derangements in sympathetic activation and regulation that may be driven by increased inflammation. Fourth, our cohort included a small sample size and was entirely comprised of medically healthy military Veterans and predominantly composed of African American men; therefore, our results may not be generalizable to other racial groups, women, non-Veteran populations or Veterans with comorbid medical diseases such as hypertension or other cardiovascular disease. African American men, however, remain both an at-risk group for hypertension and an understudied population; thus, our findings may help advance the care of African American men living with PTSD. Fifth, the severe PTSD subgroup had a higher proportion of participants treated with prazosin; however, although prazosin reportedly has anti-inflammatory effects(Wang et al., 2018), we detected higher inflammation with increasing severity of PTSD. Sixth, there was a greater proportion of patients with MDD in the severe PTSD group, although not statistically significant. However, after adjustment for MDD, the PC analysis as well as most individual biomarkers except for hsCRP remained higher with increasing severity of PTSD. Increases in hsCRP in severe PTSD may be more driven by comorbid MDD (Chamberlain et al., 2019). Finally, the smoking status of the participants was self-reported and obtained from the medical records. We did not test for serum cotinine levels.

In summary, a growing number of studies (Willerson \& Ridker, 2004; Golia et al., 2014; Ruparelia et al., 2017; Howard et al., 2018) in recent years have highlighted the role of inflammation as an early mechanism contributing to the development of cardiovascular diseases. Our findings that demonstrate that the severity of PTSD symptoms are associated with higher inflammation, as well as greater impairment of arterial baroreflex sensitivity, higher resting heart rates, and exaggerated PNS withdrawal may mechanistically explain the epidemiologic observations that link higher psychological symptoms in PTSD with even greater risk of cardiovascular disease. However, the current study does not establish causality, and a reverse causality, where individuals with autonomic imbalance and increased inflammation, might be more susceptible to developing PTSD after a traumatic event is also possible. A higher severity of PTSD symptoms not only contributes to increased psychological distress, but is also associated with higher risk of hypertension and cardiovascular disease that may be mediated by greater inflammation and autonomic dysfunction. Finally, these results might have treatment implications. Early pharmacologic and nonpharmacologic interventions aimed at reducing inflammation and sympathetic activity, as well as the treatment of PTSD symptoms themselves, particularly in severe PTSD, may have long-term beneficial effects on cardiovascular disease risk and should be investigated in future studies. 


\section{Acknowledgments}

FUNDING: This work was supported by Merit Review Award number I01CX001065 from the United States Department of Veterans Affairs (VA) Clinical Sciences Research and Development Program; American Heart Association National Affiliate, Collaborative Sciences Award 15CSA24340001; National Institutes of Health (NIH) R01 HL135183; NIH training grant T32 DK-00756; Department of Veterans Affairs, Veterans Health Administration, Office of Research and Development and the Clinical Studies Center of the Atlanta VA Health Care System, Decatur, Georgia; and Foundation for Atlanta Veterans Education and Research (FAVER).

\section{REFERENCES}

Baker DG, Nievergelt CM \& O'Connor DT. (2012). Biomarkers of PTSD: neuropeptides and immune signaling. Neuropharmacology 62, 663-673. [PubMed: 21392516]

Bedi US \& Arora R. (2007). Cardiovascular manifestations of posttraumatic stress disorder. J Natl Med Assoc 99, 642-649. [PubMed: 17595933]

Blake DD, Weathers F, Nagy L, Kaloupek D, Klauminzer G, Charney D, Keane T \& Buckley TC. (2000). INSTRUCTION MANUAL CLINICIAN-ADMINISTERED PTSD SCALE (CAPS). National Center for PTSD.

Blake DD, Weathers FW, Nagy LM, Kaloupek DG, Gusman FD, Charney DS \& Keane TM. (1995). The development of a Clinician-Administered PTSD Scale. J Trauma Stress 8, 75-90. [PubMed: 7712061]

Blanchard EB, Jones-Alexander J, Buckley TC \& Forneris CA. (1996). Psychometric properties of the PTSD Checklist (PCL). Behav Res Ther 34, 669-673. [PubMed: 8870294]

Bonyhay I \& Freeman R. (2004). Sympathetic nerve activity in response to hypotensive stress in the postural tachycardia syndrome. Circulation 110, 3193-3198. [PubMed: 15533861]

Bovin MJ, Marx BP, Weathers FW, Gallagher MW, Rodriguez P, Schnurr PP \& Keane TM. (2016). Psychometric properties of the PTSD Checklist for Diagnostic and Statistical Manual of Mental Disorders-Fifth Edition (PCL-5) in veterans. Psychological assessment 28, 1379-1391. [PubMed: 26653052]

Bremner JD, Krystal JH, Southwick SM \& Charney DS. (1996). Noradrenergic mechanisms in stress and anxiety: II. Clinical studies. Synapse (New York, NY) 23, 39-51.

Bristow JD, Honour AJ, Pickering GW, Sleight P \& Smyth HS. (1969). Diminished baroreflex sensitivity in high blood pressure. Circulation 39, 48-54. [PubMed: 4302539]

Buckley TC \& Kaloupek DG. (2001). A meta-analytic examination of basal cardiovascular activity in posttraumatic stress disorder. Psychosomatic medicine 63, 585-594. [PubMed: 11485112]

Burg MM, Brandt C, Buta E, Schwartz J, Bathulapalli H, Dziura J, Edmondson DE \& Haskell S. (2017). Risk for Incident Hypertension Associated With Posttraumatic Stress Disorder in Military Veterans and the Effect of Posttraumatic Stress Disorder Treatment. Psychosom Med 79, 181-188. [PubMed: 27490852]

Carter JR \& Ray CA. (2009). Sympathetic neural responses to mental stress: responders, nonresponders and sex differences. American journal of physiology Heart and circulatory physiology 296, H847-853. [PubMed: 19168718]

Chamberlain SR, Cavanagh J, de Boer P, Mondelli V, Jones DNC, Drevets WC, Cowen PJ, Harrison NA, Pointon L, Pariante CM \& Bullmore ET. (2019). Treatment-resistant depression and peripheral C-reactive protein. The British journal of psychiatry : the journal of mental science 214 , 11-19. [PubMed: 29764522]

Chang HA, Chang CC, Tzeng NS, Kuo TB, Lu RB \& Huang SY. (2013). Decreased cardiac vagal control in drug-naive patients with posttraumatic stress disorder. Psychiatry Investig 10, 121-130.

Chapleau MW, Li Z, Meyrelles SS, Ma X \& Abboud FM. (2001). Mechanisms determining sensitivity of baroreceptor afferents in health and disease. Ann N Y Acad Sci 940, 1-19. [PubMed: 11458669]

Chida Y \& Steptoe A. (2010). Greater cardiovascular responses to laboratory mental stress are associated with poor subsequent cardiovascular risk status: a meta-analysis of prospective evidence. Hypertension (Dallas, Tex : 1979) 55, 1026-1032. 
Dada N, Kim NW \& Wolfert RL. (2002). Lp-PLA2: an emerging biomarker of coronary heart disease. Expert review of molecular diagnostics 2, 17-22. [PubMed: 11963798]

Edmondson D \& Cohen BE. (2013). Posttraumatic stress disorder and cardiovascular disease. Progress in cardiovascular diseases 55, 548-556. [PubMed: 23621964]

Edmondson D \& von Känel R. (2017). Post-traumatic stress disorder and cardiovascular disease. The lancet Psychiatry 4, 320-329. [PubMed: 28109646]

Fichorova RN, Richardson-Harman N, Alfano M, Belec L, Carbonneil C, Chen S, Cosentino L, Curtis K, Dezzutti CS, Donoval B, Doncel GF, Donaghay M, Grivel J-C, Guzman E, Hayes M, Herold B, Hillier S, Lackman-Smith C, Landay A, Margolis L, Mayer KH, Pasicznyk J-M, PallanschCokonis M, Poli G, Reichelderfer P, Roberts P, Rodriguez I, Saidi H, Sassi RR, Shattock R \& Cummins JJE. (2008). Biological and Technical Variables Affecting Immunoassay Recovery of Cytokines from Human Serum and Simulated Vaginal Fluid: A Multicenter Study. Analytical Chemistry 80, 4741-4751. [PubMed: 18484740]

Fonkoue IT, Le NA, Kankam ML, DaCosta D, Jones TN, Marvar PJ \& Park J. (2019). Sympathoexcitation and impaired arterial baroreflex sensitivity are linked to vascular inflammation in individuals with elevated resting blood pressure. Physiological reports 7, e14057. [PubMed: 30968587]

Fonkoue IT, Marvar PJ, Norrholm SD, Kankam ML, Li Y, DaCosta D, Rothbaum BO \& Park J. (2018a). Acute effects of device-guided slow breathing on sympathetic nerve activity and baroreflex sensitivity in posttraumatic stress disorder. American journal of physiology Heart and circulatory physiology 315, H141-h149. [PubMed: 29652544]

Fonkoue IT, Norrholm SD, Marvar PJ, Li Y, Kankam ML, Rothbaum BO \& Park J. (2018b). Elevated resting blood pressure augments autonomic imbalance in posttraumatic stress disorder. American journal of physiology Regulatory, integrative and comparative physiology 315, R1272-r1280.

Fonkoue IT, Wang M \& Carter JR. (2016). Sympathetic neural reactivity to mental stress in offspring of hypertensive parents: 20 years revisited. Am J Physiol Heart Circ Physiol 311, H426-432. [PubMed: 27371684]

Geracioti TD Jr., Baker DG, Ekhator NN, West SA, Hill KK, Bruce AB, Schmidt D, Rounds-Kugler B, Yehuda R, Keck PE Jr. \& Kasckow JW. (2001). CSF norepinephrine concentrations in posttraumatic stress disorder. The American journal of psychiatry 158, 1227-1230. [PubMed: 11481155]

Gill JM, Saligan L, Woods S \& Page G. (2009). PTSD is associated with an excess of inflammatory immune activities. Perspectives in psychiatric care 45, 262-277. [PubMed: 19780999]

Golia E, Limongelli G, Natale F, Fimiani F, Maddaloni V, Pariggiano I, Bianchi R, Crisci M, D’Acierno L, Giordano R, Di Palma G, Conte M, Golino P, Russo MG, Calabro R \& Calabro P. (2014). Inflammation and cardiovascular disease: from pathogenesis to therapeutic target. Current atherosclerosis reports 16, 435. [PubMed: 25037581]

Hansen TW, Thijs L, Boggia J, Li Y, Kikuya M, Bjorklund-Bodegard K, Richart T, Ohkubo T, Jeppesen J, Torp-Pedersen C, Lind L, Sandoya E, Imai Y, Wang J, Ibsen H, O'Brien E \& Staessen JA. (2008). Prognostic value of ambulatory heart rate revisited in 6928 subjects from 6 populations. Hypertension (Dallas, Tex : 1979) 52, 229-235.

Herder C, de Las Heras Gala T, Carstensen-Kirberg M, Huth C, Zierer A, Wahl S, Sudduth-Klinger J, Kuulasmaa K, Peretz D, Ligthart S, Bongaerts BWC, Dehghan A, Ikram MA, Jula A, Kee F, Pietila A, Saarela O, Zeller T, Blankenberg S, Meisinger C, Peters A, Roden M, Salomaa V, Koenig W \& Thorand B. (2017). Circulating Levels of Interleukin 1-Receptor Antagonist and Risk of Cardiovascular Disease: Meta-Analysis of Six Population-Based Cohorts. Arteriosclerosis, thrombosis, and vascular biology 37, 1222-1227.

Hillebrand S, Gast KB, de Mutsert R, Swenne CA, Jukema JW, Middeldorp S, Rosendaal FR \& Dekkers OM. (2013). Heart rate variability and first cardiovascular event in populations without known cardiovascular disease: meta-analysis and dose-response meta-regression. Europace : European pacing, arrhythmias, and cardiac electrophysiology : journal of the working groups on cardiac pacing, arrhythmias, and cardiac cellular electrophysiology of the European Society of Cardiology 15, 742-749. 
Howard JT, Sosnov JA, Janak JC, Gundlapalli AV, Pettey WB, Walker LE \& Stewart IJ. (2018). Associations of Initial Injury Severity and Posttraumatic Stress Disorder Diagnoses With LongTerm Hypertension Risk After Combat Injury. Hypertension (Dallas, Tex : 1979) 71, 824-832.

Ilies C, Bauer M, Berg P, Rosenberg J, Hedderich J, Bein B, Hinz J \& Hanss R. (2012). Investigation of the agreement of a continuous non-invasive arterial pressure device in comparison with invasive radial artery measurement. Br J Anaesth 108, 202-210. [PubMed: 22171358]

James PA, Oparil S, Carter BL, Cushman WC, Dennison-Himmelfarb C, Handler J, Lackland DT, LeFevre ML, MacKenzie TD, Ogedegbe O, Smith SC Jr., Svetkey LP, Taler SJ, Townsend RR, Wright JT Jr., Narva AS \& Ortiz E. (2014). 2014 evidence-based guideline for the management of high blood pressure in adults: report from the panel members appointed to the Eighth Joint National Committee (JNC 8). Jama 311, 507-520. [PubMed: 24352797]

Johansson M, Ehnvall A, Friberg P \& Myredal A. (2010). Arterial baroreflex dysfunction in major depressive disorder. Clin Auton Res 20, 235-240. [PubMed: 20127136]

Jolliffe IT \& Cadima J. (2016). Principal component analysis: a review and recent developments. Philosophical Transactions of the Royal Society A: Mathematical, Physical and Engineering Sciences 374.

Kaptoge S, Di Angelantonio E, Lowe G, Pepys MB, Thompson SG, Collins R \& Danesh J. (2010). Creactive protein concentration and risk of coronary heart disease, stroke, and mortality: an individual participant meta-analysis. Lancet 375, 132-140. [PubMed: 20031199]

Kessler RC, Berglund P, Demler O, Jin R, Merikangas KR \& Walters EE. (2005). Lifetime prevalence and age-of-onset distributions of DSM-IV disorders in the National Comorbidity Survey Replication. Archives of general psychiatry 62, 593-602. [PubMed: 15939837]

Le NA, Tomassini JE, Tershakovec AM, Neff DR \& Wilson PW. (2015). Effect of Switching From Statin Monotherapy to Ezetimibe/Simvastatin Combination Therapy Compared With Other Intensified Lipid-Lowering Strategies on Lipoprotein Subclasses in Diabetic Patients With Symptomatic Cardiovascular Disease. Journal of the American Heart Association 4, e001675. [PubMed: 26486166]

Leviton A, Fichorova R, Yamamoto Y, Allred EN, Dammann O, Hecht J, Kuban K, McElrath T, O'Shea TM \& Paneth N. (2011). Inflammation-related proteins in the blood of extremely low gestational age newborns. The contribution of inflammation to the appearance of developmental regulation. Cytokine 53, 66-73. [PubMed: 20934883]

Lindqvist D, Wolkowitz OM, Mellon S, Yehuda R, Flory JD, Henn-Haase C, Bierer LM, Abu-Amara D, Coy M, Neylan TC, Makotkine I, Reus VI, Yan X, Taylor NM, Marmar CR \& Dhabhar FS. (2014). Proinflammatory milieu in combat-related PTSD is independent of depression and early life stress. Brain, behavior, and immunity 42, 81-88.

Malik M, Bigger JT, Camm AJ, Kleiger RE, A. M, A.J. M \& P.J. S. (1996). Heart rate variability. Standards of measurement, physiological interpretation, and clinical use. Task Force of the European Society of Cardiology and the North American Society of Pacing and Electrophysiology. European heart journal 17, 354-381. [PubMed: 8737210]

Mano T, Iwase S \& Toma S. (2006). Microneurography as a tool in clinical neurophysiology to investigate peripheral neural traffic in humans. Clin Neurophysiol 117, 2357-2384. [PubMed: 16904937]

Marvar PJ, Hendy EB, Cruise TD, Walas D, DeCicco D, Vadigepalli R, Schwaber JS, Waki H, Murphy D \& Paton JF. (2016). Systemic leukotriene B4 receptor antagonism lowers arterial blood pressure and improves autonomic function in the spontaneously hypertensive rat. The Journal of physiology.

Matsukawa T, Gotoh E, Hasegawa O, Shionoiri H, Tochikubo O \& Ishii M. (1991a). Reduced baroreflex changes in muscle sympathetic nerve activity during blood pressure elevation in essential hypertension. Journal of hypertension 9, 537-542. [PubMed: 1653293]

Matsukawa T, Gotoh E, Uneda S, Miyajima E, Shionoiri H, Tochikubo O \& Ishii M. (1991b). Augmented sympathetic nerve activity in response to stressors in young borderline hypertensive men. Acta Physiol Scand 141, 157-165. [PubMed: 2048404]

Minassian A, Geyer MA, Baker DG, Nievergelt CM, O’Connor DT \& Risbrough VB. (2014). Heart rate variability characteristics in a large group of active-duty marines and relationship to posttraumatic stress. Psychosomatic medicine 76, 292-301. [PubMed: 24804881] 
Minassian A, Maihofer AX, Baker DG, Nievergelt CM, Geyer MA \& Risbrough VB. (2015). Association of Predeployment Heart Rate Variability With Risk of Postdeployment Posttraumatic Stress Disorder in Active-Duty Marines. JAMA psychiatry 72, 979-986. [PubMed: 26353072]

Nasr N, Pavy-Le Traon A \& Larrue V. (2005). Baroreflex sensitivity is impaired in bilateral carotid atherosclerosis. Stroke 36, 1891-1895. [PubMed: 16100025]

Neta R, Sayers TJ \& Oppenheim JJ. (1992). Relationship of TNF to interleukins. Immunology series 56, 499-566. [PubMed: 1550874]

Pace TW \& Heim CM. (2011). A short review on the psychoneuroimmunology of posttraumatic stress disorder: from risk factors to medical comorbidities. Brain, behavior, and immunity 25, 6-13.

Park J, Marvar PJ, Liao P, Kankam ML, Norrholm SD, Downey RM, McCullough SA, Le NA \& Rothbaum BO. (2017). Baroreflex dysfunction and augmented sympathetic nerve responses during mental stress in veterans with post-traumatic stress disorder. J Physiol 595, 4893-4908. [PubMed: 28503726]

Pole N (2007). The psychophysiology of posttraumatic stress disorder: a meta-analysis. Psychological bulletin 133, 725-746. [PubMed: 17723027]

Ray CA \& Monahan KD. (2002). Sympathetic vascular transduction is augmented in young normotensive blacks. Journal of applied physiology (Bethesda, Md : 1985) 92, 651-656.

Reid JL \& Vincent J. (1986). Clinical pharmacology and therapeutic role of prazosin and related alphaadrenoceptor antagonists. Cardiology 73, 164-174. [PubMed: 2872958]

Rudas L, Crossman AA, Morillo CA, Halliwill JR, Tahvanainen KU, Kuusela TA \& Eckberg DL. (1999). Human sympathetic and vagal baroreflex responses to sequential nitroprusside and phenylephrine. Am J Physiol 276, H1691-1698. [PubMed: 10330255]

Ruparelia N, Chai JT, Fisher EA \& Choudhury RP. (2017). Inflammatory processes in cardiovascular disease: a route to targeted therapies. Nature reviews Cardiology 14, 133-144. [PubMed: 27905474]

Rusch HL, Robinson J, Yun S, Osier ND, Martin C, Brewin CR \& Gill JM. (2019). Gene expression differences in PTSD are uniquely related to the intrusion symptom cluster: A transcriptome-wide analysis in military service members. Brain, behavior, and immunity.

Sarwar N, Butterworth AS, Freitag DF, Gregson J, Willeit P, Gorman DN, Gao P, Saleheen D, Rendon A, Nelson CP, Braund PS, Hall AS, Chasman DI, Tybjaerg-Hansen A, Chambers JC, Benjamin EJ, Franks PW, Clarke R, Wilde AA, Trip MD, Steri M, Witteman JC, Qi L, van der Schoot CE, de Faire U, Erdmann J, Stringham HM, Koenig W, Rader DJ, Melzer D, Reich D, Psaty BM, Kleber ME, Panagiotakos DB, Willeit J, Wennberg P, Woodward M, Adamovic S, Rimm EB, Meade TW, Gillum RF, Shaffer JA, Hofman A, Onat A, Sundstrom J, Wassertheil-Smoller S, Mellstrom D, Gallacher J, Cushman M, Tracy RP, Kauhanen J, Karlsson M, Salonen JT, Wilhelmsen L, Amouyel P, Cantin B, Best LG, Ben-Shlomo Y, Manson JE, Davey-Smith G, de Bakker PI, O'Donnell CJ, Wilson JF, Wilson AG, Assimes TL, Jansson JO, Ohlsson C, Tivesten A, Ljunggren O, Reilly MP, Hamsten A, Ingelsson E, Cambien F, Hung J, Thomas GN, Boehnke M, Schunkert H, Asselbergs FW, Kastelein JJ, Gudnason V, Salomaa V, Harris TB, Kooner JS, Allin KH, Nordestgaard BG, Hopewell JC, Goodall AH, Ridker PM, Holm H, Watkins H, Ouwehand WH, Samani NJ, Kaptoge S, Di Angelantonio E, Harari O \& Danesh J. (2012). Interleukin-6 receptor pathways in coronary heart disease: a collaborative meta-analysis of 82 studies. Lancet (London, England) 379, 1205-1213.

Seal KH, Metzler TJ, Gima KS, Bertenthal D, Maguen S \& Marmar CR. (2009). Trends and risk factors for mental health diagnoses among Iraq and Afghanistan veterans using Department of Veterans Affairs health care, 2002-2008. American journal of public health 99, 1651-1658. [PubMed: 19608954]

Shah AJ, Lampert R, Goldberg J, Veledar E, Bremner JD \& Vaccarino V. (2013). Posttraumatic stress disorder and impaired autonomic modulation in male twins. Biol Psychiatry 73, 1103-1110. [PubMed: 23434412]

Shalev AY, Sahar T, Freedman S, Peri T, Glick N, Brandes D, Orr SP \& Pitman RK. (1998). A prospective study of heart rate response following trauma and the subsequent development of posttraumatic stress disorder. Archives of general psychiatry 55, 553-559. [PubMed: 9633675]

Tadic M, Cuspidi C \& Grassi G. (2018). Heart rate as a predictor of cardiovascular risk. European journal of clinical investigation 48 . 
Takagishi M, Waki H, Bhuiyan ME, Gouraud SS, Kohsaka A, Cui H, Yamazaki T, Paton JF \& Maeda M. (2010). IL-6 microinjected in the nucleus tractus solitarii attenuates cardiac baroreceptor reflex function in rats. American journal of physiology Regulatory, integrative and comparative physiology 298, R183-190.

Tomiyama H, Shiina K, Matsumoto-Nakano C, Ninomiya T, Komatsu S, Kimura K, Chikamori T \& Yamashina A. (2017). The Contribution of Inflammation to the Development of Hypertension Mediated by Increased Arterial Stiffness. Journal of the American Heart Association 6.

Vaccarino V, Goldberg J, Rooks C, Shah AJ, Veledar E, Faber TL, Votaw JR, Forsberg CW \& Bremner JD. (2013). Post-traumatic stress disorder and incidence of coronary heart disease: a twin study. J Am Coll Cardiol 62, 970-978. [PubMed: 23810885]

von Kanel R, Begre S, Abbas CC, Saner H, Gander ML \& Schmid JP. (2010). Inflammatory biomarkers in patients with posttraumatic stress disorder caused by myocardial infarction and the role of depressive symptoms. Neuroimmunomodulation 17, 39-46. [PubMed: 19816056]

von Kanel R, Hepp U, Kraemer B, Traber R, Keel M, Mica L \& Schnyder U. (2007). Evidence for low-grade systemic proinflammatory activity in patients with posttraumatic stress disorder. $\mathrm{J}$ Psychiatr Res 41, 744-752. [PubMed: 16901505]

Wallin BG \& Fagius J. (1988). Peripheral sympathetic neural activity in conscious humans. Annu Rev Physiol 50, 565-576. [PubMed: 3288106]

Wang L, Xue Y, Ma H, Shi H, Wang L \& Cui X. (2018). Prazosin protects myocardial cells against anoxia-reoxygenation injury via the extracellular signalregulated kinase signaling pathway. Molecular medicine reports 17, 2145-2152. [PubMed: 29207167]

Weathers FW, Keane TM \& Davidson JR. (2001). Clinician-administered PTSD scale: a review of the first ten years of research. Depress Anxiety 13, 132-156. [PubMed: 11387733]

Whelton PK, Carey RM, Aronow WS, Casey DE Jr., Collins KJ, Dennison Himmelfarb C, DePalma SM, Gidding S, Jamerson KA, Jones DW, MacLaughlin EJ, Muntner P, Ovbiagele B, Smith SC Jr., Spencer CC, Stafford RS, Taler SJ, Thomas RJ, Williams KA Sr., Williamson JD \& Wright JT Jr. (2018). 2017 ACC/AHA/AAPA/ABC/ACPM/AGS/APhA/ASH/ASPC/NMA/PCNA Guideline for the Prevention, Detection, Evaluation, and Management of High Blood Pressure in Adults: A Report of the American College of Cardiology/American Heart Association Task Force on Clinical Practice Guidelines. Journal of the American College of Cardiology 71, e127-e248. [PubMed: 29146535]

White DW \& Raven PB. (2014). Autonomic neural control of heart rate during dynamic exercise: revisited. J Physiol 592, 2491-2500. [PubMed: 24756637]

Willerson JT \& Ridker PM. (2004). Inflammation as a cardiovascular risk factor. Circulation 109, Ii210. [PubMed: 15173056]

Wingenfeld K, Whooley MA, Neylan TC, Otte C \& Cohen BE. (2015). Effect of current and lifetime posttraumatic stress disorder on 24-h urinary catecholamines and cortisol: results from the Mind Your Heart Study. Psychoneuroendocrinology 52, 83-91. [PubMed: 25459895]

Woodward M, Webster R, Murakami Y, Barzi F, Lam TH, Fang X, Suh I, Batty GD, Huxley R \& Rodgers A. (2014). The association between resting heart rate, cardiovascular disease and mortality: evidence from 112,680 men and women in 12 cohorts. European journal of preventive cardiology 21, 719-726. [PubMed: 22718796]

Zhang D, Shen X \& Qi X. (2016). Resting heart rate and all-cause and cardiovascular mortality in the general population: a meta-analysis. CMAJ : Canadian Medical Association journal = journal de l'Association medicale canadienne 188, E53-e63. 


\section{Highlights}

- Symptom severity in posttraumatic stress disorder (PTSD) affects autonomic function, regulation, and inflammation.

- Increasing PTSD symptom severity is linked to greater impairment in cardiovagal baroreflex sensitivity and elevated resting heart rate.

- $\quad$ Patients with more severe PTSD symptoms have increased inflammation and exaggerated withdrawal of parasympathetic activation during mental stress. 


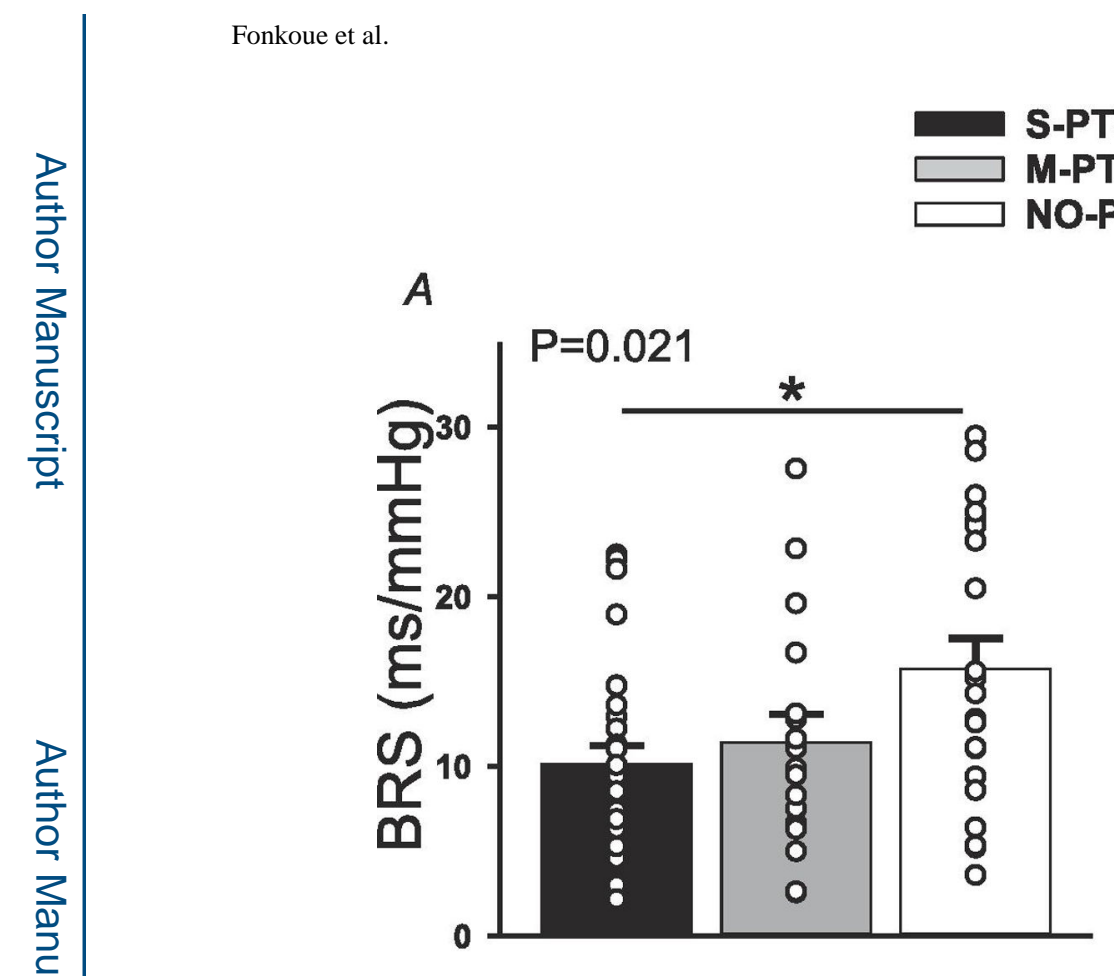

$B$

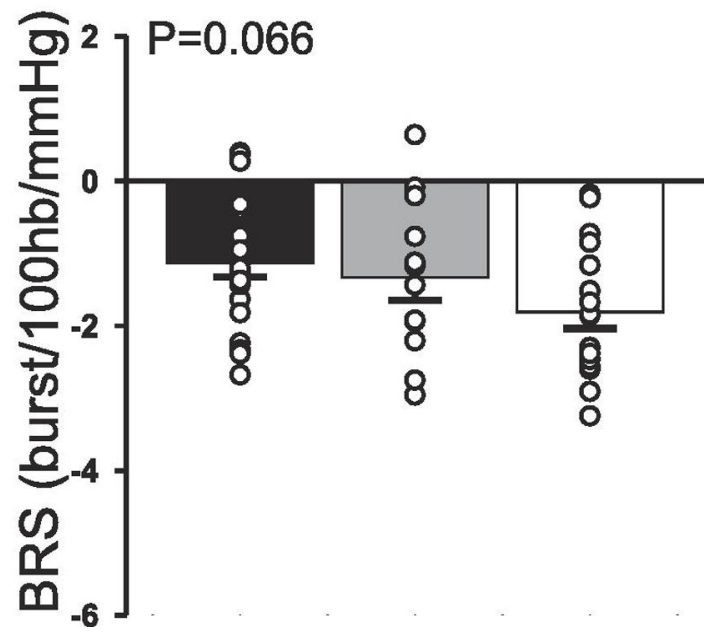

Figure 1:

Cardiovagal (panel $A$ ) and sympathetic (panel $B$ ) baroreflex sensitivity (BRS) at rest. Cardiovagal BRS was blunted in 28 with severe posttraumatic stress disorder (S-PTSD) compared to 16 with moderate PTSD (M-PTSD) and 26 Controls (NO-PTSD). Sympathetic BRS tended to be blunted in 26 S-PTSD compared to 13 M-PTSD and 22 Controls. * $\mathrm{p}<0.05$. 


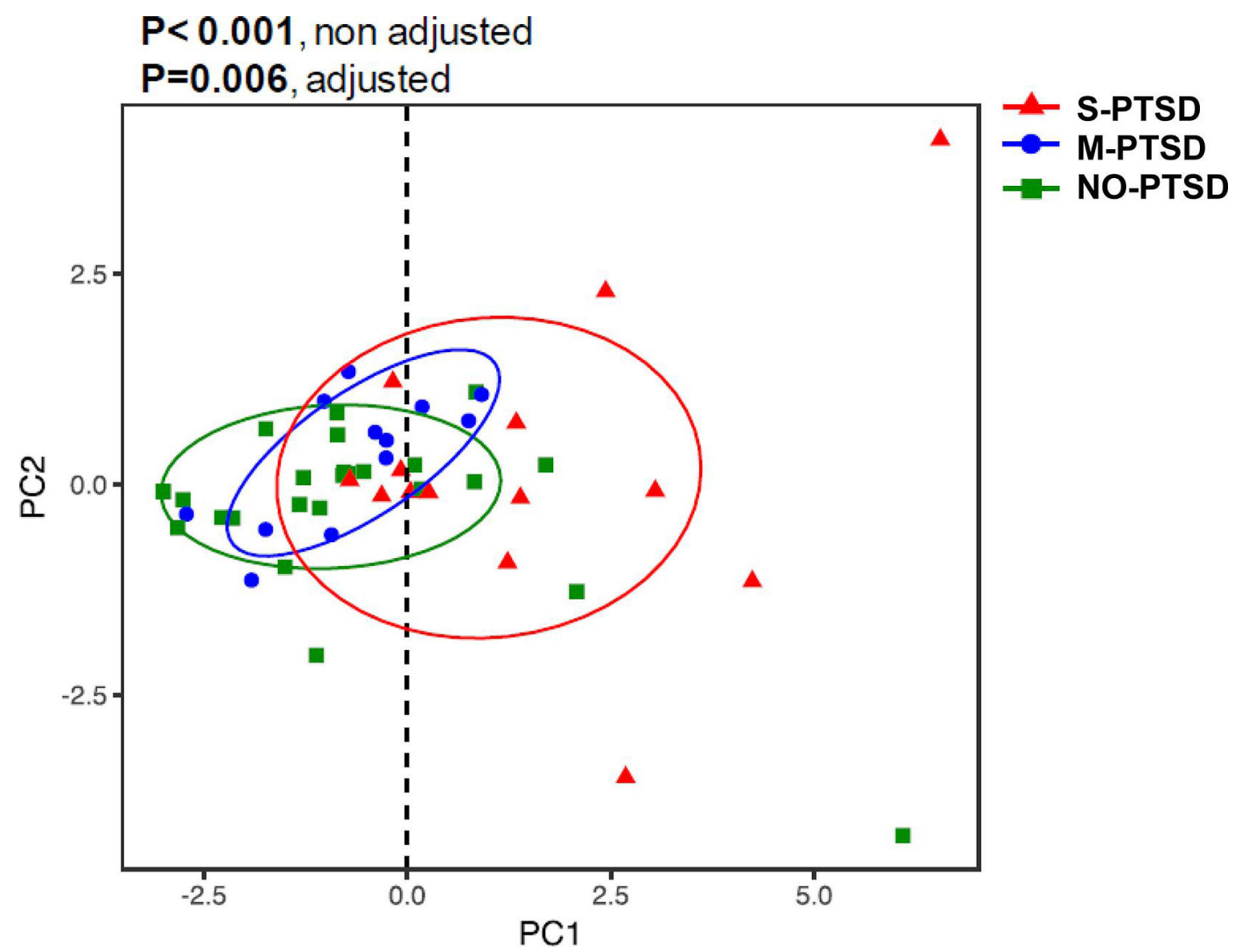

Figure 2:

Combined inflammatory scores using principal component (PC) analysis for 14 with severe posttraumatic stress disorder (S-PTSD), 12 with moderate PTSD (M-PTSD) and 24 Controls (NO-PTSD). Inflammatory scores were higher in S-PTSD compared to M-PTSD and NOPTSD. * $\mathrm{p}<0.05$. 
A

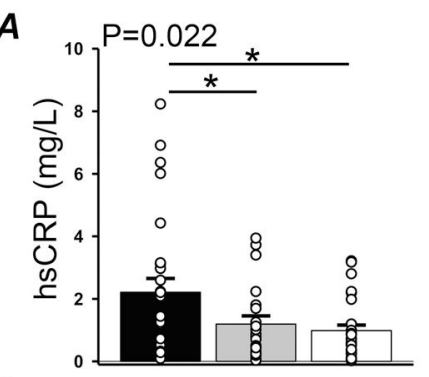

C

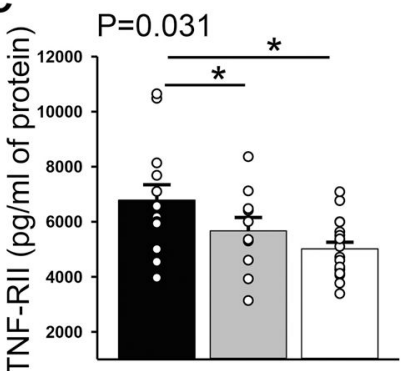

E

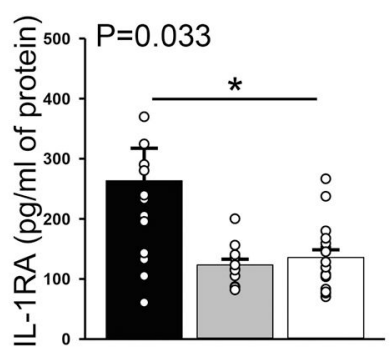

$\boldsymbol{G}$

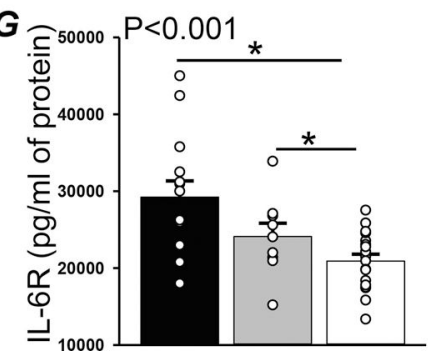

$B$
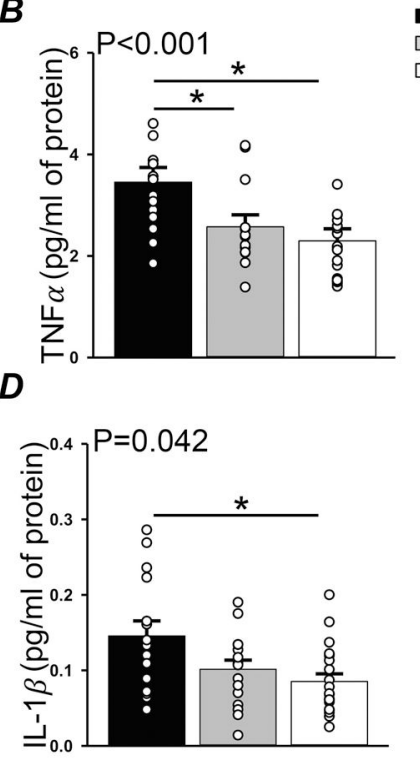

$F$
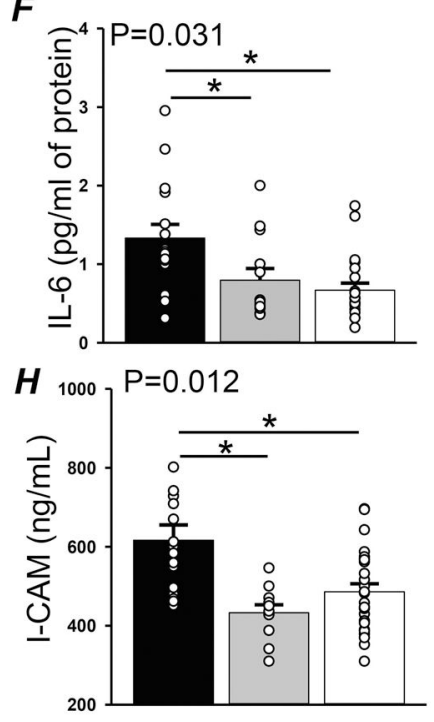

Figure 3:

Highly sensitive C-reactive protein (hsCRP; panel $A$ ), tumor necrosis factor a (TNFa; panel $B$ ), TNF receptor II ( TNF-RII; panel $C$ ), interleukin $1 \beta$ (IL-1 $\beta$; panel $D$ ), IL-1 receptor A ( IL-1RA; panel $E$ ), interleukin 6 (IL-6; panel F), IL-6 receptor (IL-6R; panel G) and intercellular adhesion molecule (I-CAM; panel H) at rest in 14 with severe posttraumatic stress disorder (S-PTSD), 12 with moderate PTSD (M-PTSD) and 24 Controls (NO-PTSD). $* \mathrm{p}<0.05$. 

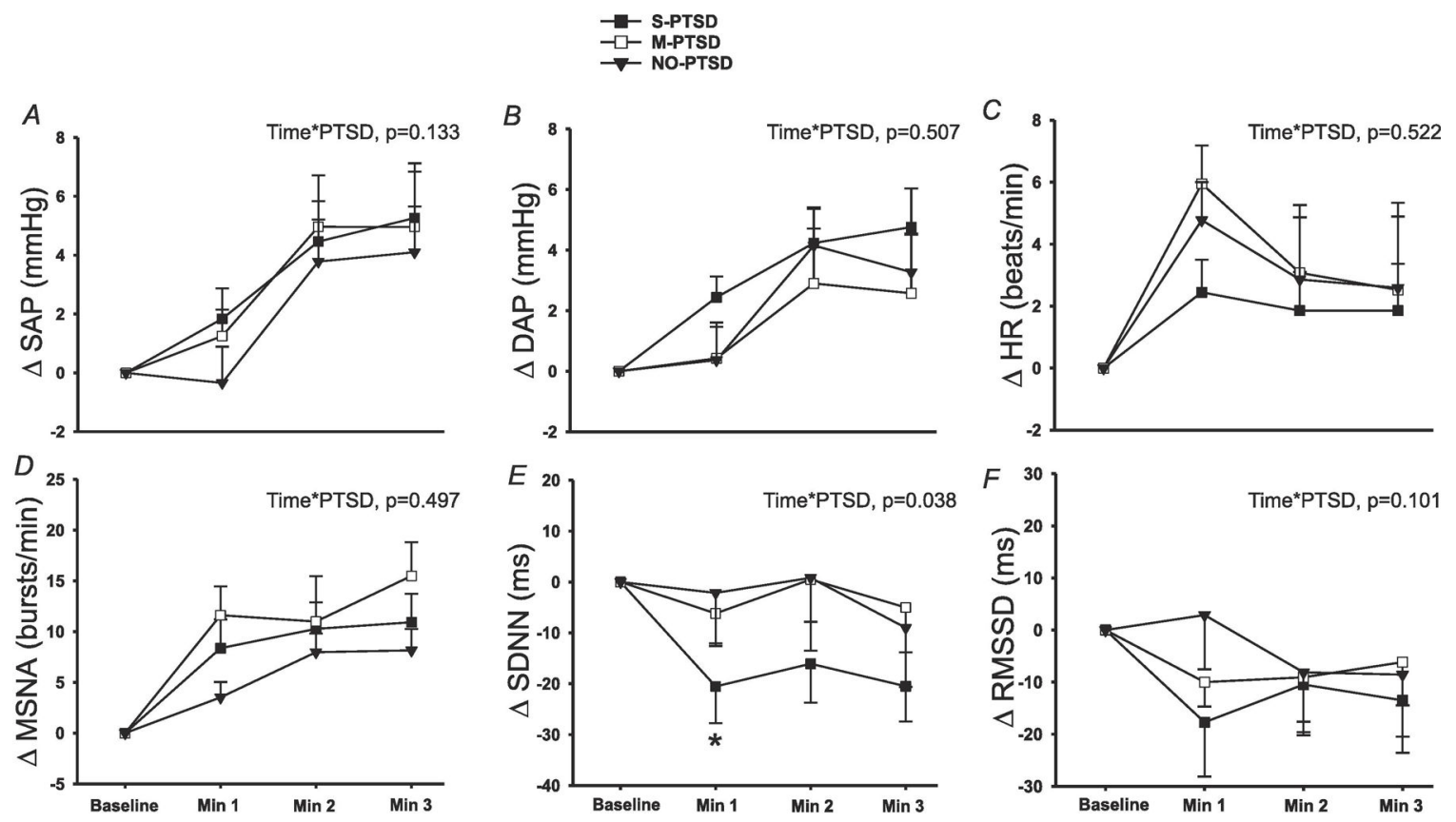

Figure 4:

Changes in systolic arterial pressure (SAP; panel A), diastolic arterial pressure (DAP; panel B), heart rate (HR; panel C), standard deviation of normal R-R intervals (SDNN; panel E) and root mean square of the successive differences (RMSSD; panel F) during 3 min of mental stress in 28 with severe posttraumatic stress disorder (S-PTSD) compared to 16 with moderate PTSD (M-PTSD) and 26 Controls (NO-PTSD). Change in muscle sympathetic nerve activity (MSNA; panel D) in 26 S-PTSD compared to 13 M-PTSD and 22 Controls. SDNN reactivity to mental stress was significantly blunted in S-PTSD compared with MPTSD and NO-PTSD. SAP, DAP, HR, MSNA and RMSSD reactivity to mental stress were not different between the groups. A linear mixed-model analysis was used to assess the within-group and between-group differences. $* P<0.05$ 
Table 1:

Baseline Characteristics (sample of $\mathrm{n}=70$ )

\begin{tabular}{|l|c|c|c|c|}
\hline Variable & $\begin{array}{c}\text { S-PTSD } \\
(\mathbf{n = 2 8})\end{array}$ & $\begin{array}{c}\text { M-PTSD } \\
(\mathbf{n = 1 6})\end{array}$ & $\begin{array}{c}\text { NO-PTSD } \\
(\mathbf{n = 2 6})\end{array}$ & P-value \\
\hline Age(years) & $39 \pm 2$ & $35 \pm 2$ & $35 \pm 2$ & 0.153 \\
\hline BMI (kg/m²) & $30 \pm 1$ & $29 \pm 1$ & $28 \pm 1$ & 0.587 \\
\hline Race (B/W) & $25 / 3$ & $12 / 4$ & $22 / 4$ & 0.515 \\
\hline Sex (M/F) & $20 / 8$ & $11 / 5$ & $20 / 6$ & 0.683 \\
\hline CAPS-IV score & $82 \pm 3$ & $53 \pm 2$ & $38 \pm 1$ & $<0.001^{*}$ \\
\hline PCL-M score & $71 \pm 2$ & $55 \pm 4$ & $33 \pm 2$ & $<0.001$ \\
\hline Smoking (Yes/No) & $11 / 17$ & $4 / 12$ & $4 / 22$ & 0.132 \\
\hline SSRI (Yes/No) & $14 / 14$ & $5 / 11$ & $5 / 21$ & 0.061 \\
\hline MDD (Yes/No) & $13 / 15$ & $4 / 12$ & $7 / 19$ & 0.215 \\
\hline Prazosin (Yes/No) & $9 / 19$ & $3 / 13$ & $0 / 26$ & 0.007 \\
\hline SAP (mmHg) & $119 \pm 2$ & $120 \pm 3$ & $122 \pm 2$ & 0.518 \\
\hline DAP (mmHg) & $78 \pm 1$ & $77 \pm 3$ & $80 \pm 2$ & 0.489 \\
\hline HR (beats/min) & $76 \pm 2$ & $70 \pm 3$ & $67 \pm 2$ & 0.055 \\
\hline MSNA (burst/min) & $23 \pm 2$ & $20 \pm 3$ & $24 \pm 3$ & 0.443 \\
\hline MSNA (burst/100hb) & $35 \pm 3$ & $32 \pm 4$ & $39 \pm 3$ & 0.477 \\
\hline SDNN (ms) & $72 \pm 6$ & $67 \pm 7$ & $80 \pm 8$ & 0.470 \\
\hline RMSSD (ms) & $58 \pm 7$ & $52 \pm 6$ & $68 \pm 8$ & 0.368 \\
\hline
\end{tabular}

Values are mean \pm SE. S-PTSD, severe PTSD; M-PTSD, moderate PTSD; NO-PTSD, no PTSD or controls; BMI, body mass index; CAPS-IV, Clinician Administered PTSD Scale IV; PCL-M, PTSD CheckList - Military version; SSRI, selective serotonin receptor inhibitors; MDD, major depressive disorder; SAP, systolic arterial pressure; DAP, diastolic arterial pressure; HR, heart rate; MSNA, muscle sympathetic nerve activity; heart beats; SDNN, standard deviation of R-R intervals; RMSSD; root mean square of differences in successive R-R intervals. p-values are twotailed.

$\mathrm{p}<0.05$.

For MSNA, n= 26 S-PTSD, 13 M-PTSD and 22 NO-PTSD. For CAPS-IV, N=34. For PCL-M, n=59. 